\title{
Outcome of Colorectal cancer in Geriatric Patient
}

\author{
Ashfaq Chandio*, Anil Rai, Mehak Chandio, Asirvatham Rhody, Katherine Brown \\ Department of Colorectal Surgery, Luton \& Dunstable University Hospital, UK.
}

*Corresponding Author: Ashfaq Chandio, Department of Colorectal Surgery, Luton \& Dunstable University Hospital, UK.

Received Date: August 11, 2021; Accepted Date: August 20, 2021; Published Date: August 30, 2021

Citation: A Chandio, A Rai, M Chandio, R Asirvatham, K Brown. (2021) Outcome of Colorectal cancer in Geriatric Patient. J. Cancer Research and Cellular Therapeutics. 5(4); Doi: 10.31579/2640-1053/094

Copyright: () 2021 Ashfaq Chandio, This is an open-access article distributed under the terms of the Creative Commons Attribution License, which permits unrestricted use, distribution, and reproduction in any medium, provided the original author and source are credited.

\begin{abstract}
Background: Older surgical patients remain at increased risk of adverse postoperative outcome when undergoing both elective and emergency surgery. The needs of the older surgical patient are often substantially different from those of younger patients. As a surgeons we have dilemmas in appropriately treating elderly patients. Specifically, those with cancer have been shown to receive inappropriate care, being either undertreated or overtreated based on their chronological age rather than their degree of frailty.
\end{abstract}

Aim: To evaluate outcome of patients diagnosed with colorectal cancer in patients aged 80 years and over.

Methods: Retrospective study of all patients 80 years and above managed with colorectal cancer at the Luton and Dunstable University Hospital UK from January 2015 through December 2019

Results: In the study period 278 patients were diagnosed with colorectal cancer, Male 143 Female 135 ratio 1:1.05. Age range from 80 to 101 years. $54.31 \%$ patients underwent surgical intervention. $15.10 \%$ had complications after surgery. $36.69 \%$ patients deemed unsuitable for resection surgery were treated with best supportive care palliatively. $57.19 \%$ patients were in ASAIII, 24.10\% ASAII and 12.23\% ASAIV. 46.40\% patients died during the study period.

Conclusion: Age on its own would not be taken as for less aggressive therapy; Careful assessment of the patient taking into consideration comorbidities, functional status and patient wishes are essential in decision making and choosing appropriate management plan. Curative surgery for colorectal carcinoma in the geriatric patients are well tolerated. Management of comorbidities preceding surgery may impact postoperative outcome.

Keywords: Colorectal cancer; Geriatric Patient; emergency surgery

\section{Introduction:}

Older surgical patients remain at increased risk of adverse postoperative outcome when undergoing both elective and emergency surgery. This may be due to patient or procedural factors, or both. The needs of the older surgical patient are often substantially different from those of younger patients. There is lack of consensus about the definition of age to be considered as the cut off for geriatric patients ( 65 vs 70 vs 75 years old), though there is consensus that patients should not be treated based on their age alone [1]. As a surgeons we have dilemmas in appropriately treating elderly patients. Specifically, those with cancer have been shown to receive inappropriate care, being either undertreated or overtreated based on their chronological age rather than their degree of frailty [2]. Prompt identification of high risk and frail patients helps to establish an appropriate care pathway, reduce morbidity and mortality and direct hospital resources [3]. Colorectal cancer is a major health problem. In the $\mathrm{UK}$, it is the second most common cause of cancer death. $5 \%$ of UK population is at risk of colorectal carcinoma during lifetime, more than nine out of ten new cases (94\%) are diagnosed in people over the age of
50 , and nearly six out of ten cases (59\%) are diagnosed in people aged 70 or over [4]. Bowel cancer can affect anyone of any age, incidence and mortality rates vary markedly around the world. Care of elderly surgical patients is complex and patients are often treated inappropriately based on their age, degree of frailty, or both. It is therefore crucial to assess frailty and identify areas of intervention before surgery is undertaken. Advances in surgical, anaesthetic, and intensive care techniques have consequently led to a larger proportion of this increasing elderly population presenting to undergo surgical procedures $[5,6]$.

\section{Aim:}

To evaluate outcome of patients diagnosed with colorectal cancer in patients aged 80 years and over.

\section{Methods:}

All patients 80 years and above managed with colorectal cancer at the Luton and Dunstable University Hospital UK from January 2015 through December 2019 were retrospectively identified from the referral database 
maintained by the colorectal specialist nurses in the colorectal service. Data were retrieved by detailed review of the hospital case notes on ICE and Evolve (Computer database for investigations and correspondence) including endoscopy; radiographic imaging; operative course and cancer follow up. The following parameters were recorded: age, gender, and source of referral, presentation, stage of the disease, MDT discussion, intervention, and outcome. Tumour locations were classified as the right colon (i.e. caecum, ascending colon, hepatic flexure, transverse colon, and left colon (i.e. spleenic flexure, descending colon, sigmoid, Recto sigmoid, and rectum.

Inclusion: All patients diagnosed with colorectal cancer 80 years and above

Exclusion: Patients under 80 years of age, Colo Rectal Cancer of unknown primary site. Anal cancer, Appendix, Small bowel carcinoma

\section{Statistical Analysis}

Data were analyzed using the Statistical Package for Social Sciences (SPSS, version 26). Patient age was normally distributed, and the mean and standard deviation was calculated. Survival was calculated from the date of diagnosis (as recorded in the MDT discussion) to the date of death or last confirmed survival. Kaplan Meier survival curves were constructed and significance tested using the log-rank test. The level of significance was set at a $\mathrm{p}<0.05$. Mean values were compared using the Student $t$ test.
Univariate analysis of categorical variables was performed by the chisquare test. Pearson's chi squared test was used for comparing two proportions. An OR with corresponding 95\% confidence interval >1 implied a positive association where as an OR with corresponding 95\% confidence interval $<1$ implied a negative association. Two-sided $p$ values $<0.05$ were considered significant. The results are mainly illustrated by descriptive statistics. Fisher's exact and Student's t tests were used to compare the frequencies of both categorical and continuous variables

\section{Results:}

In the study period 278 patients were diagnosed with colorectal cancer, Male (143) Female (135) ratio 1:1.05. (Fig: 1)The mean age of 85.44 years (range, 80 to 101years). $151(54.31 \%)$ patients underwent surgical intervention. $102(36.69 \%)$ patients deemed unsuitable for resection surgery were treated with best supportive care palliatively. (Table 1) American Society of Anaesthesiologist (ASA grade) 57.19\% (159) patients were in ASAIII, $24.10 \%$ (67) ASAII and 12.23\% (34) ASAIV. (Table 2) In the Right colon subset of patients there was a total of $43.16 \%$ patients 70 Female and 50 Male, (Table 3) in $38.48 \%$ patients with Left Colon cancer there were 64 Male and 43 Female. (Table 4) Of $17.26 \%$ Rectal cancer patients there were 25 Male and 23 Female. (Table 5). 42 $(15.10 \%)$ had complications after surgery (Table). $12946.40 \%$ patients died during the study period. Incidence of colorectal cancer was greater for cancers of the left side of colon than right colon. (55.75\% vs $43.16 \%)$.

\begin{tabular}{|l|r|r|r|r|r|r|}
\hline Site & Female & Male & Died & Surgery & Palliative & \multicolumn{1}{l|}{ Total } \\
\hline Caecum & 39 & 29 & 31 & 39 & 24 & 68 \\
Asc. Colon & 17 & 14 & 11 & 21 & 5 & 31 \\
Hep. Flexure & 6 & 9 & 4 & 12 & 3 & 15 \\
Transverse & 8 & 3 & 4 & 5 & 6 & 11 \\
Spl. flexure & 3 & 4 & 4 & 3 & 4 & 7 \\
Descending & 6 & 7 & 6 & 5 & 6 & 13 \\
Sigmoid & 27 & 42 & 38 & 41 & 24 & 70 \\
Recto & 6 & 10 & & 6 & & \\
sigmoid & 23 & 25 & 21 & 19 & 8 & 16 \\
Rectum & 135 & 143 & $128(46.04 \%)$ & $151(54.31 \%)$ & $102(36.69 \%)$ & 278 \\
\hline Total & & & & 22 & 48 \\
\hline
\end{tabular}

Table 1

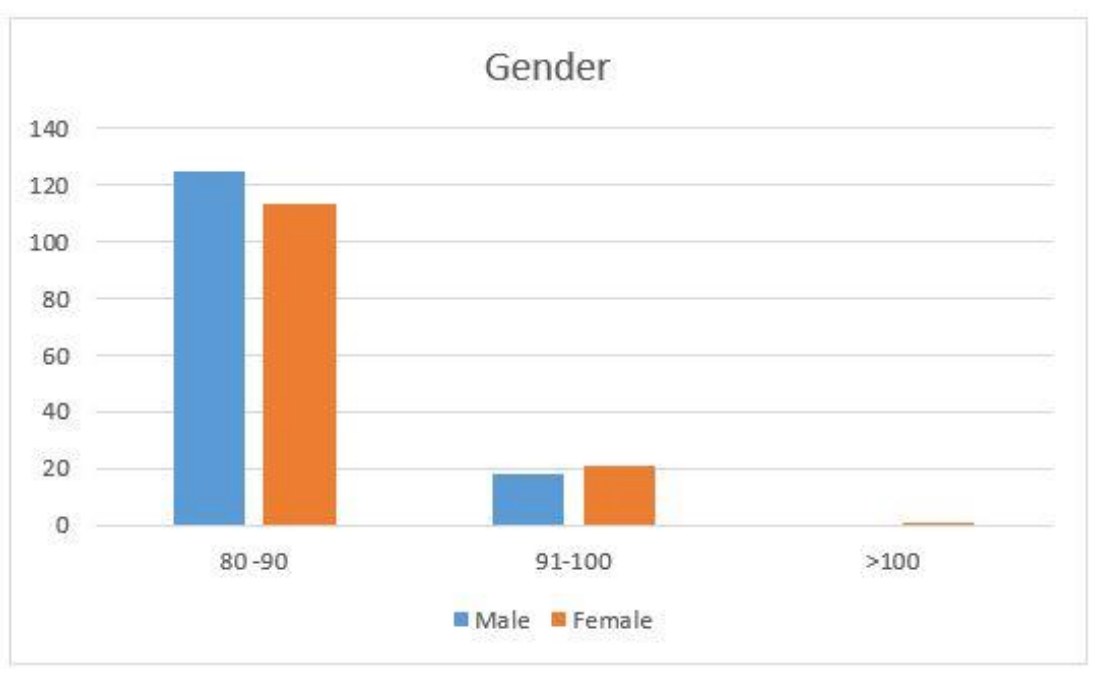

Figure 1 


\begin{tabular}{|r|r|r|r|l|}
\hline \multicolumn{7}{|c|}{ ASA grade } \\
\hline $\mathbf{2}$ & $\mathbf{2}$ & $\mathbf{3}$ & $\mathbf{4}$ & No record \\
\hline 9 & 67 & 159 & & 18 \\
$(3.23 \%)$ & $(24.10 \%)$ & $(57.19 \%)$ & $34(12.23 \%)$ & $(6.47 \%)$ \\
\hline
\end{tabular}

Table 2

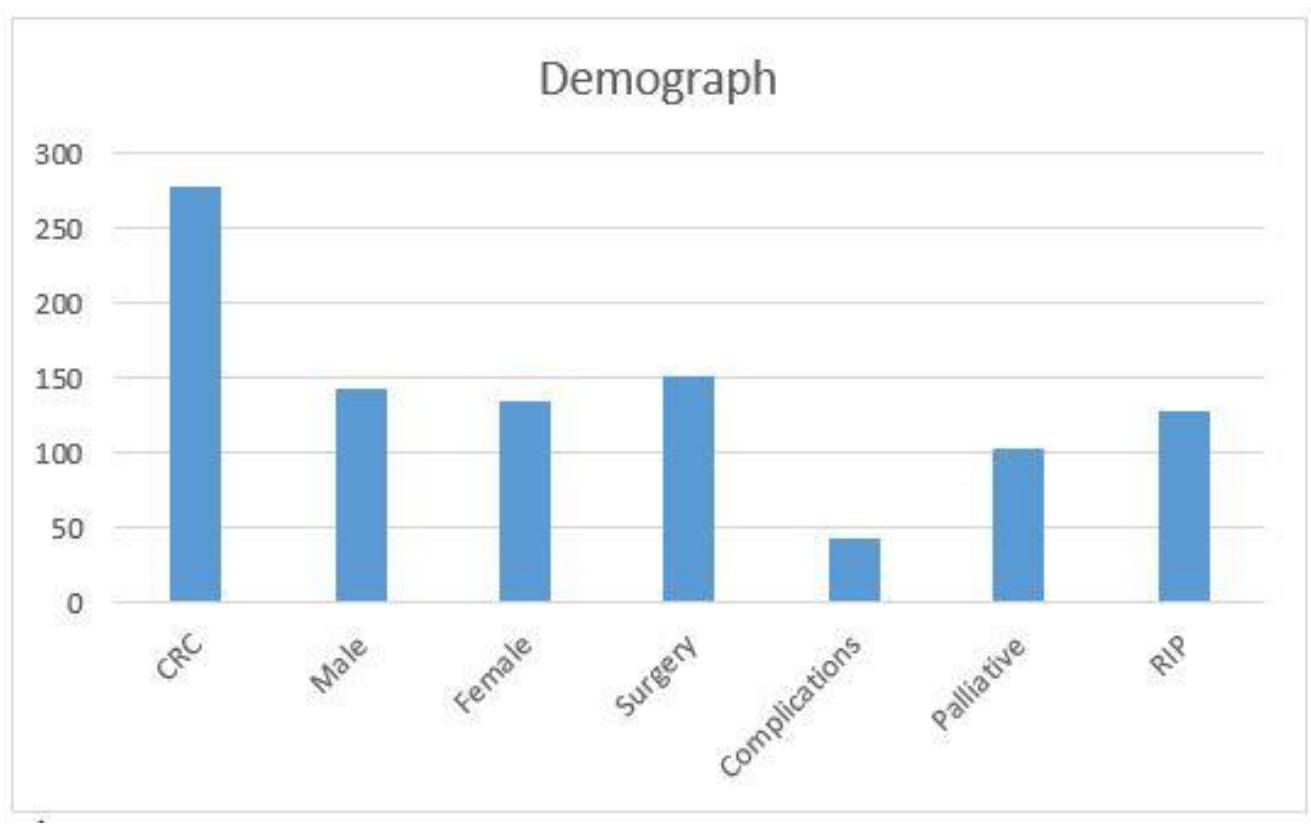

Figure 2

\begin{tabular}{|lr|r|r|r|r|r|}
\hline \multicolumn{7}{|c|}{$\begin{array}{l}\text { Right } \\
\text { colon }\end{array}$} \\
\hline & Female & \multicolumn{1}{|l|}{ Male } & Died & Surgery & Palliative \\
\hline & & & & & & \\
Caecum & 68 & 39 & 29 & 31 & 39 & 24 \\
Asc. Colon & 31 & 17 & 14 & 11 & 21 & 5 \\
Hepatic & 15 & 6 & 9 & 4 & 12 & 3 \\
Flexure & 11 & 8 & 3 & 4 & 5 & 6 \\
Transverse & 125 & 70 & 55 & 50 & 77 & 38 \\
\hline & $(44.96 \%)$ & $(25.17 \%)$ & $(19.78 \%)$ & $(17.98 \%)$ & $(27.69 \%)$ & $(13.66 \%)$ \\
\hline
\end{tabular}

Table 3 


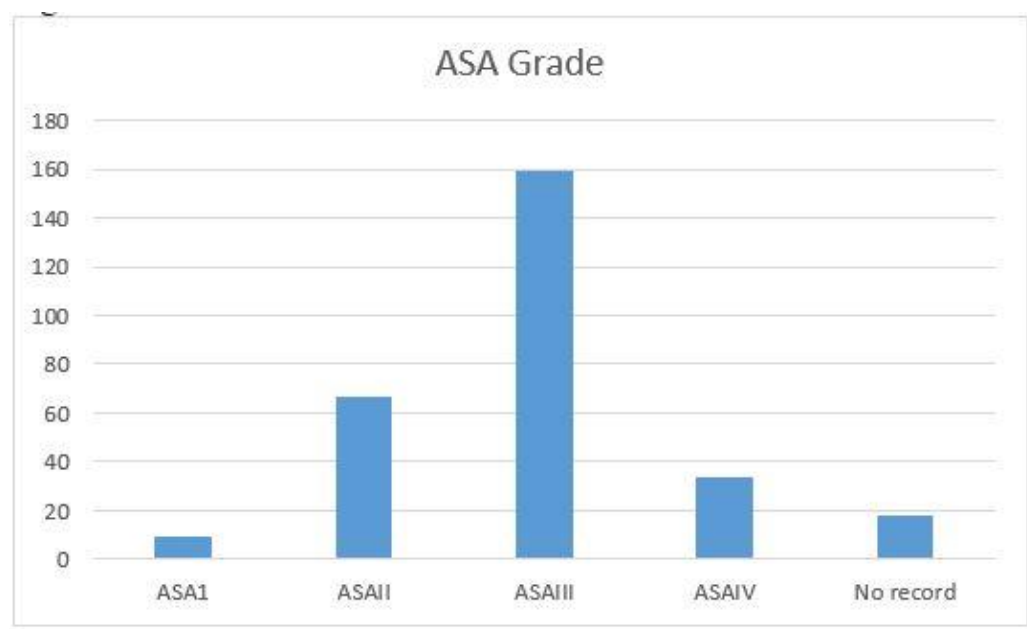

Figure 3

\begin{tabular}{|lr|r|r|r|r|r|}
\hline \multicolumn{7}{|c|}{ Left colon } \\
\hline & & Female & \multicolumn{1}{l|}{ Male } & Died & Surgery & Palliative \\
\hline & & & & & & \\
Spleenic & 7 & 3 & 4 & 4 & & \\
flexure & 13 & 6 & 7 & 6 & 5 & 4 \\
Descending & 69 & 27 & 42 & 38 & 41 & 6 \\
Sigmoid & 16 & 6 & 10 & 9 & 6 & \\
Recto & 105 & 42 & 63 & 57 & 55 & 42 \\
sigmoid & $(37.76 \%)$ & $(15.10 \%)$ & $(22.66 \%)$ & $(20.50 \%)$ & $(19.78 \%)$ & $(15.10 \%)$ \\
\hline & & & & & \\
Total & & & & & \\
\hline
\end{tabular}

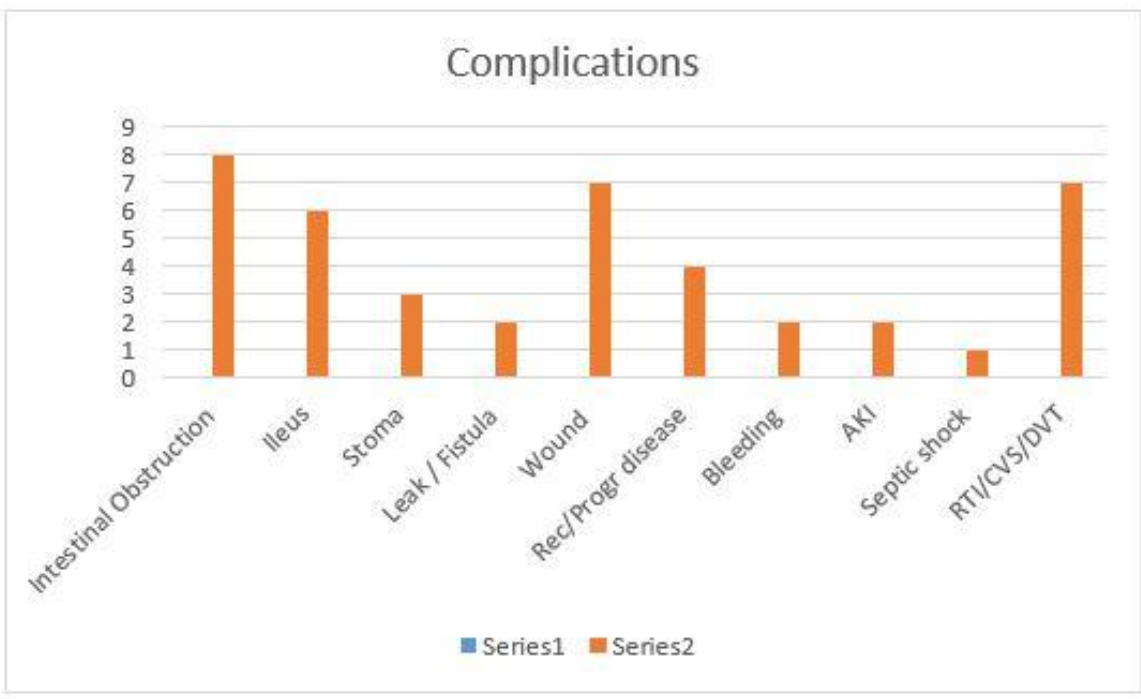

Figure 4 


\begin{tabular}{|c|c|c|c|c|c|}
\hline \multicolumn{6}{|c|}{ Rectum } \\
\hline & Female & Male & Died & Surgery & Palliative \\
\hline Rectum & 23 & 25 & 21 & 19 & 22 \\
\hline 48 & 23 & 25 & 21 & 19 & 22 \\
\hline$(17.26 \%)$ & $(8.27 \%)$ & $(8.99 \%)$ & $(7.5 \%)$ & $(6.83 \%)$ & (7.91\%) \\
\hline
\end{tabular}

Table 5

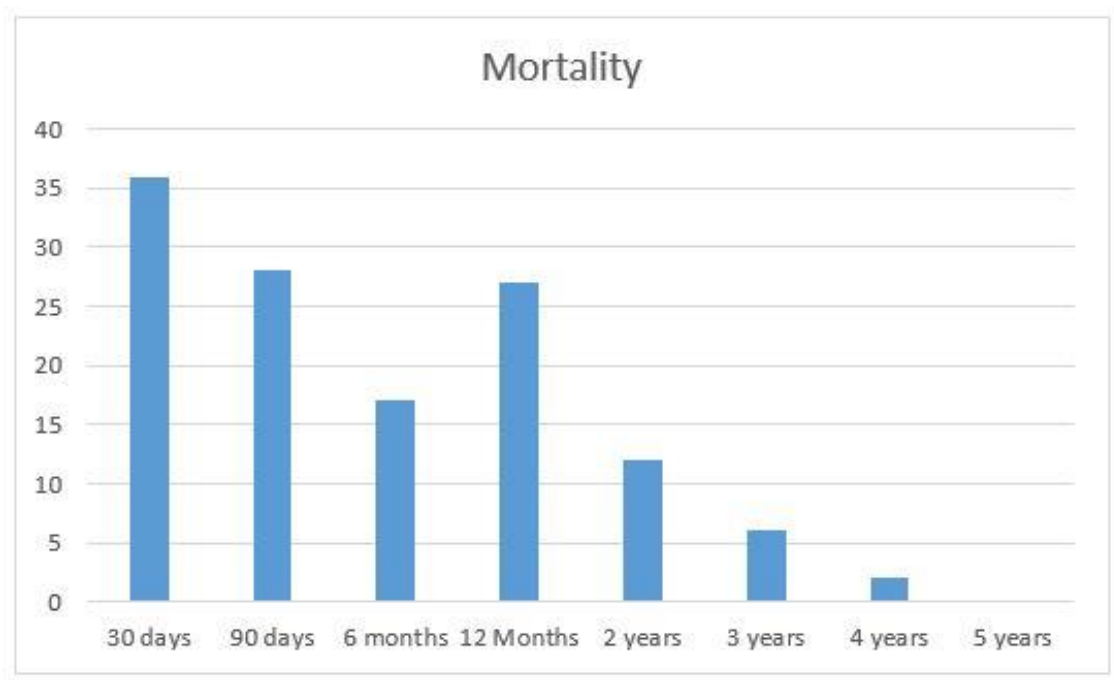

Figure 5

\section{Discussion:}

Colorectal cancer is a common and lethal cancer worldwide, more than nine out of ten new cases (94\%) are diagnosed in people over the age of 50 , and nearly six out of ten cases $(59 \%)$ are diagnosed in people aged 70 or over, bowel cancer can affect anyone of any age, $30 \%$ of patients with Colorectal cancer present with a metastatic disease [7,8].

The elderly and frail Geriatric patients are exposed to high risks of morbidity and mortality when undergoing both emergency and elective surgery. This is due to patient or procedural factors or both. Identification of these factors in the elective setting through multimodal structured assessment preoperatively, through multidisciplinary input, allows optimisation of pre-existing medical conditions and appropriate multidisciplinary pre, peri and postoperative care. Older patients are more likely to present with co-existent age-related frailty, co-morbidities and age related disorders. As age increases, the rates of surgical complications remain fairly static, though medical complications are more often observed [9]. These medical complications include organ specific, for example acute kidney injury, respiratory tract problems , atrial fibrillation, and geriatric disorders including delirium, falls, dysphagia, this encounters challenges when considering whether to operate or not. Patients and family are expected to query: What happens if I don't have a operation? Certainly, all patients should now expect a full explanation of all the possible treatment options available to them, and clinicians are legally bound to present these equably [10].

Management of colorectal cancer in the aged population poses its unique challenges. An increasingly elderly population combined with colon cancer rates increasing $1.4-2.5$ fold with each consecutive decade of life will considerably increase the prevalence of colorectal cancer in in the coming years [11].Furthermore, improved awareness, better access to investigations and the appreciation that chronological age is no longer a barrier to individualised treatment renders colorectal cancer increasingly important in this age group. It is therefore, better to speak of biological age rather than chronological age whilst evaluating risk factors for surgery, which focuses more on the overall patient condition. As management options in colonic cancer increase, literature shows a decrease in the rate of resection comparing younger patients and the elderly [12]. Colorectal cancer survival is considerably better when the diagnosis is made at an early stage, making a convincing case for early detection through screening programs [13]. However, most patients with colorectal cancers are diagnosed after the onset of cancer-related symptoms [14] and it is imperative that frontline providers recognize early diagnostic clues to colorectal cancer. Studies have shown that rectal bleeding as an initial presentation of colon cancer and are associated with an early stage of the disease and better survival $[15,16]$ Colorectal Cancer incidence can be separated into $72 \%$ for the colon and $28 \%$ for the rectum, but colon and rectal cancer mortality are generally reported together [17] The location of colon cancer is also changing. The colonic distribution of cancer has had a relative rightward shift over the past 3 decades [18]. In our study we found $82.85 \%$ of cancer were in the colon and $17.14 \%$ were in the rectum. Waldron and Donovan revealed that $23 \%$ of colorectal tumours were right sided [19] Crerand S, Freely TM, Waldron RP, et al study in Dublin revealed that approximately $28 \%$ of colorectal tumours were right sided [20] and Hayne D, Brown RS, McCormack M, et al study on the current trends of colorectal cancer in England and Wales concluded that approximately $29 \%$ of colorectal cancers were right sided [21].this is in contrast to our study, we found Right colon cancer was $44.64 \%$. The findings from our study suggest Left colon cancer was $38.21 \%$ and $17.14 \%$ of cancer were in the Rectum this is similar to other published 
studies [22, 23]. Our study show that age is not a predictor of postoperative complications. This is similar to other published studies [2427]. The choice of treatment is based on several factors, including conditions of the patient stage at presentation, and the location of tumour. Surgery remains the core in curative treatment for colorectal cancer. Because of the steadily increase in the elder population, surgeons will be confronted with more and more elderly patients. While choosing treatment options, quality of life and function may be at least as important for the elderly as the cancer specific or surgical outcome [28]. In our study surgery was performed in $(53.92 \%)$. Specific problems associated with geriatric patients are, multiple comorbidities, prolonged hospital stay, and a delayed presentation. In our study $92.85 \%$ of the patients at the time of surgery had one or more comorbidity, most of the patients were ASA III grade $(56.78 \%)$, this is similar to other published studies [29, 30]. The elderly frail may be good candidates for palliative care, which can provide a better quality of remaining life. It is a troublesome to decide when to begin palliative care but when frailty is severe, delivery of palliative care focused on relief of discomfort and enhancement of quality of life.

One of the strengths of our study is that the sample size is not small, Patients admitted as an emergency and scheduled for elective surgery for confirmed colorectal cancer aged 80 and above were included and long follow-up period. The limitations of this study is single center, retrospective

Elderly patients are the largest group of cancer patients, and there is rapidly increasing number. In spite of the high incidence of Colorectal cancer and the high prevalence of colorectal cancer related morbidity and mortality, elderly patients are under-presented in clinical trials [31]. When managing geriatric patients with comorbidity and poor performance status, oncologists have a limited number of treatment options. Several published reports have shown that a colorectal cancer resection in elderly patients is associated with neither higher postoperative mortality, complications, nor worse short term oncological outcome [32, 33]. In our study $15.10 \%$ had complications after surgery $46.40 \%$ patients died during the study period. The outcomes of colorectal cancer surgery in geriatric patients could be comparable to those in younger patients without in- creasing the postoperative morbidity and mortality rates.

Assessment of fitness for surgery in the elderly need more holistic than in the general population, involves consideration of cardiorespiratory fitness, other comorbidities, frailty and quality of life.

\section{Conclusion:}

Age on its own would not be taken as for less aggressive therapy; Careful assessment of the patient taking into consideration comorbidities, functional status and patient wishes are essential in decision making and choosing appropriate management plan. Curative surgery for colorectal carcinoma in the geriatric patients are well tolerated. Management of comorbidities preceding surgery may impact postoperative outcome.

\section{References}

1. Shahrokni A, Alexander K. (2019). The age of talking about age alone is over. Ann Surg Oncol. 26:12-14.

2. Lawler M, Selby P, Aapro MS, Duffy S. (2014). Ageism in cancer care. BMJ. 348:16-14.

3. Sebranek JJ, Lugli AK, Coursin DB. (2013). Glycaemic control in the perioperative period. Br J Anaesth. 111(Suppl 1): 18-34

4. American Cancer Society. (2017). Colorectal Cancer Facts \& Figures 2017-2019. Atlanta: American Cancer Society.

5. Owens WD. (1988). Overview of anesthesia for the geriatric patient. Int Anesthesiol Clin. 26(2):96-97.

6. Veering BT. (1999). Management of anaesthesia in elderly patients. Curr Opin Anaesthesiol. 12(3):333-336.

7. Torre LA, Bray F, Siegel RL, Ferlay J, Lortet-Tieulent J, Jemal A.
(2015). Global cancer statistics, 2012. CA Cancer J Clin. 65: 87-108. 8. Schmoll HJ, Van Cutsem E, Stein A, Valentini V, Glimelius B, Haustermans K, Nordlinger B, van de Velde CJ, Balmana J, Regula J, Nagtegaal ID, Beets-Tan RG, Arnold D, Ciardiello F, Hoff P, Kerr D, Köhne CH, Labianca R, Price T, Scheithauer W, Sobrero A, Tabernero J, Aderka D, Barroso S, Bodoky G, Douillard JY, El Ghazaly H, Gallardo J, Garin A, Glynne-Jones R, Jordan K, Meshcheryakov A, Papamichail D, Pfeiffer P, Souglakos I, Turhal S, Cervantes A. (2012). ESMO Consensus Guidelines for management of patients with colon and rectal cancer. a personalized approach to clinical decision making. Ann Oncol. 23: 2479-2516.

9. Patel SA, Zenilman ME. (2001). Outcomes in older people undergoing operative intervention for colorectal cancer. Journal of the American Geriatrics Society. 49: 1561-1564.

10. Montgomery (Appellant) v Lanarkshire Health Board (Respondent), (2015).

11. National Population Projections, 2012-based Statistical Bulletin. Office for National Statistics.

12. A.M. Bouvier, G. Launoy, C. (2005). Lepage, and J. Faivre, "Trends in the management and survival of digestive tract cancers among patients aged over 80 years," Alimentary Pharmacology and Therapeutics, vol. 22, no. 3, pp. 233-241.

13. Levin B, Lieberman DA, McFarland B, et al. (2008). Screening and surveillance for the early detection of colorectal cancer and adenomatous polyps, 2008: A Joint Guideline from the American Cancer Society, the US Multi-Society Task Force on Colorectal Cancer, and the American College of Radiology. CA Cancer J Clin. 58: 130-60.

14. Hamilton W, Sharp D. (2004). Diagnosis of colorectal cancer in primary care: the evidence base for guidelines. Fam Pract. 21: 99106.

15. Stapley S, Peters TJ, Sharp D, Hamilton W. (2006). The mortality of colorectal cancer in relation to the initial symptom at presentation to primary care and to the duration of symptoms: a cohort study using medical records. Br J Cancer. 95: 1321-1325.

16. Korsgaard M, Pedersen L, Sorensen HT, Laurberg S. (2006). Reported symptoms, diagnostic delay and stage of colorectal cancer: a population-based study in Denmark. Colorectal Dis. 8: 688-695.

17. Cancer Facts Figures 2011.

18. Cucino C, Buchner AM, Sonnenberg A. (2002). Continued rightward shift of colorectal cancer. Dis Colon Rectum. 45:10351040.

19. Waldron RP, Donovan IA. (1986). Mortality in patients with obstructing colorectal cancer. Ann R Coll Surg Engl. 68:219-221.

20. Crerand S, Freely TM, Waldron RP, et al. (1991). Colorectal carcinoma over 30 years at one hospital: no evidence of a shift to the right. Int J Colorectal Dis. 6:184-187.

21. Hayne D, Brown RS, McCormack M, et al. (2001). Current trends in colorectal cancer: site, incidence, mortality and survival in England and Wales. Clin Oncol. 13:448-452.

22. Bray F, Ferlay J, Soerjomataram I, et al. (2018). Global cancer statistics 2018: GLOBOCAN estimates of incidence and mortality worldwide for 36 cancers in 185 countries. CA Cancer J Clin. 68: 394-424.

23. Ferlay J, Ervik M, Lam F, et al. (2018). Global Cancer Observatory: Can- cer Today. Lyon, France: International Agency for Research on Cancer.

24. Basili G, Lorenzetti L, Biondi G, Preziuso E, Angrisano C, Carnesecchi P, Roberto E, Goletti O: (2008). Colorectal cancer in the elderly. Is there a role for safe and curative surgery? ANZ J Surg. 78(6):466-470.

25. Devon KM, Vergara-Fernandez O, Victor JC, McLeod RS: (2009). Colorectal cancer surgery in elderly patients: presentation, treatment, and outcomes. Dis Colon Rectum. 52(7):1272-1277. 
26. Irvin TT: (1988). Prognosis of colorectal cancer in the elderly. Br J Surg. 75(5):419-421.

27. Paksoy M, Ipek T, Colak T, Cebeci H: (1999) Influence of age on prognosis and management of patients with colorectal carcinoma. Eur J Surg. 165(1):55-59.

28. Balducci L. (2004). Recomendaciones para el tratamiento del cancer en el anciano: Implicaciones para la calidad de vida. Rev Esp Geriatr Gerontol. 39: 270-276.

29. Terret C, Zulian G, Droz JP. (2004). Statements on the interdependence between the oncologist and the geriatrician in geriatric oncology. Crit Rev Oncol Hematol. 52: 127-133.
30. Rockwood K, Mitnitski A. Frailty defined by deficit accumulation and geriatric medicine defined by frailty. Clin Geriatr Med 2011; 27: 17-26.

31. Wildiers H, Heeren P, Puts M, et al. (2014). International Society of Geriatric Oncology Consensus on Geriatric Assessment in Older Patients with Cancer. J Clin Oncol. 32:2595-2603.

32. Yen C, Simillis C, Choudhry M, Mills' S, Warren O, Tekkis PP, et al. (2017). A comparative study of short-term outcomes of colorectal cancer surgery in the elderly population. Acta Chir Belg. 11:1-5.

33. Basso SM, Lumachi F, Pianon P, Fanti G, Maffeis F, Ubiali P. (2017). Analysis of factors affecting short-term results in elderly patients undergoing elective surgical resection for stage I-II colon cancer. Anticancer Res. 37:1971-1974.
This work is licensed under Creative Commons Attribution 4.0 License

\section{To Submit Your Article Click Here: Submit Manuscript}

DOI: $10.31579 / 2640-1053 / 094$
Ready to submit your research? Choose Auctores and benefit from:

* fast, convenient online submission

* rigorous peer review by experienced research in your field

* rapid publication on acceptance

* authors retain copyrights

* unique DOI for all articles

* immediate, unrestricted online access

At Auctores, research is always in progress.

Learn more www.auctoresonline.org/journals/cancer-research-andcellular-therapeutics 